www.jmscr.igmpublication.org

Impact Factor (SJIF): 6.379

Index Copernicus Value: 71.58

ISSN (e)-2347-176x ISSN (p) 2455-0450

crossref DOI: _https://dx.doi.org/10.18535/jmscr/v6i3.130

Journal Of Medical Science And Clinical Research

IGM Publication

An Official Publication of IGM Publication

\title{
A Comparative Study of The Effect of I.V. Esmolol And Diltiazem In Attenuating Haemodynamic Response To Laryngoscopy and endotracheal intubation
}

\author{
Authors \\ Dr Hansraj Charan ${ }^{1}$, Dr. Chiranji Lal Khedia ${ }^{2}$, Dr. Manoj Singhal ${ }^{3}$ \\ ${ }^{, 2,3}$ Assistant professor, Govt. Medical College Kota (Raj)
}

\begin{abstract}
Introduction: Laryngoscopy and tracheal intubation are noxious stimuli that evoke a transient but marked sympathetic response manifesting as hypertension and tachycardia.

They are particularly detrimental to patient with cardiovascular and intracranial diseases.

Aims and Objectives

1. To study the effect of intravenous Esmolol (B-selective blocker) and Diltiazem (Calcium channel blocker) on hemodynamic change to laryngoscopy and intubation in comparison to control group Normal saline.

2. To study the side effect and complications, if any.
\end{abstract}

Methodology: Randomized double-blind controlled study was conducted in the Department of Anesthesia, Govt. Medical College, KOTA including 111 patients.

Patients were divided in three groups of 37 each.

- Group A (Control)- ( $n=37)$ - Normal saline was given (Volume $=10 \mathrm{ml})$

- Group B (Esmolol) ( $n=37)$ - Injection Esmolol $1 \mathrm{mg} / \mathrm{kg} I . V$. bolus (diluted to $10 \mathrm{ml}$ with Normal Saline)

- Group C (Diltiazem) ( $\mathrm{n=37)}$ - Injection Diltiazem $0.2 \mathrm{mg} / \mathrm{kg} \mathrm{I} . \mathrm{V}$. bolus (diluted to $10 \mathrm{ml}$ with Normal Saline)

Results: In control group there was significant rise in heart rate just after intubation ( $p<0.05)$. The value remained significantly raised during whole study period. In the esmolol group there was small rise in HR after intubation that was significant $(p<0.05)$ but value touched the baseline within 5 min after intubation that was insignificant $(p>0.05)$ there after there was fall in HR till $10 \mathrm{~min}$. in diltiazem group there was significant. In control group there was significant rise in SBP just after intubation $(p<0.05)$. The value remained significantly raised during whole study period. In the esmolol and diltiazem group there was significant rise in SBP after intubation but value touched the baseline within 3 min in diltiazem group and within 5 min.post intubation in esmolol group $(p>0.05)$.no incidence of hypotension was observed in any of the study group.

In control group there was significant rise in MBP just after intubation ( $p<0.05)$. The value remained significantly raised during whole study period. In the esmolol and diltiazem group there was significant rise in MBP after intubation but value touched the baseline within 3 min in diltiazem group and within 5 min.post intubation in esmolol group( $p>0.05)$.no incidence of hypotension was observed in any of the study group.

It was observed that mean baseline variables (HR, SBP, DBP and MBP) were similar in the three groups and no statistically significant difference was present ( $P$ value $>0.05$ ).

Conclusion: Highly significant hemodynamic response was observed just after laryngoscopy and intubation in control group which lasted for the entire $10 \mathrm{~min}$ of the study period after intubation. Esmolol was the most effective in controlling the heart rate but ineffective in attenuating the pressure response. Diltiazem was quite effective in controlling the pressure response but it failed to achieve any control over the heart rate. No ECG abnormality and hypotension was observed in any patients in any group. 


\section{Introduction}

Endotracheal intubation is an integral part of anesthesiologist's contribution to patient care. Laryngoscopy and Tracheal intubation are one of the essential components of general anesthesia.

Besides the technical difficulty inherent to the procedure, laryngoscopy and tracheal intubation are noxious stimuli that evoke a transient but marked sympathetic response manifesting as hypertension and tachycardia.

Although these cardiovascular responses are not of great clinical significance in healthy normotensive patients but they are undesirable and may be particularly detrimental to patient with cardiovascular and intracranial diseases. The response is associated with acute left ventricular failure (Foxe et al; 1977), ischaemic ECG changes (Prys Robert et al, 1971 ${ }^{2}$ ) and ruptured cerebral aneurysm (Fox et al; $1977^{1}$ ).

Various drugs and techniques have been used in the past from time to time to attenuate these haemodynamic response. these include deepening of anesthesia (King at al; $1951^{3}$ ), Lidocaine Spray by Dehlinger et al (1976) ${ }^{4}$ opioids by Dahlgaren et al $(1981)^{5}$, Nitroglycerine by Dich Neilson J et al $(1986)^{6}$, Droperidol by curron et al $(1980)^{7}$ propanolol by Kopriva CJ et al $(1978)^{8}$, NTG ointment by Elkayam et al $(1982)^{9}$ and Calcium channel blockers (Mikawa et al, 1996) ${ }^{10}$, Fentanyl, Magnesium sulfate etc.

As today more and more patients with cardiovascular disorders are presenting themselves for surgery, anesthesiologists are in search of safest and the most efficient drug which can prevent cardiovascular response to the laryngoscopy and tracheal intubation.

The present study is set out to compare the efficacy of two different classes of drugs in attenuating the haemodynamic responses related to laryngosopy and tracheal intubation. These drugs are Esmolol (B-selective blocker) and diltiazem (calcium channel blocker).

\section{Aims and Objectives}

The present study is planned

1. To study the effect of intravenous Esmolol and Diltiazem on haemodynamic response to laryngoscopy and intubation.

2. To study the effect of intravenous Esmolol and Diltiazem on haemodynamic chang to laryngoscopy and intubation in comparison to control group Normal saline.

3. To study the side effect and complications, if any.

\section{Methodology}

- The study was conducted in the Department of Anesthesia, Govt. Medical College Kota. This randomized double-blind controlled study included 111 patients (age 20-50 years) undergoing elective surgery. Due permission from the Institutional Ethics Committee and review board and written informed patient consent was obtained.

- Study design- It's a Randomized, Double blind, Controlled study.

- The study was conducted in following three groups of the patients. Patients were divided in three groups of 37 each.

1. Group A (Control) $(\mathrm{n}=37)$ - Injection Normal saline $10 \mathrm{ml}$ I.V. 1 minute before layngoscopy and intubation.

2. Group B (Esmolol) $(\mathrm{n}=37)$ - Injection Esmolol $1 \mathrm{mg} / \mathrm{kg}$ I.V. bolus (diluted to 10 $\mathrm{ml}$ with Normal Saline) 1 minute before layngoscopy and intubation.

3. Group C (Diltiazem) $(n=37)$ - Injection Diltiazem $0.2 \mathrm{mg} / \mathrm{kg}$ I.V. bolus (diluted to $10 \mathrm{ml}$ with Normal Saline) 1 minute before laryngoscopy and intubation.

\section{Statistical Analysis}

- Analysis was done by applying parametric T-test and Anova test as applicable.

- A ' $P$ ' value of $<0.05$ was considered significant and $>0.05$ Non significant.

\section{Inclusion criteria}

1. Patients aged 20-50 yrs 
2. ASA grade I-II

3. Patients willing to give written and informed consent.

4. Patient's Weight $30-70 \mathrm{~kg}$.

\section{Exclusion criteria}

1. History of chronic disease like hypertension, varying degree of heart blocks, diabetes mellitus, respiratory disease, myopathy, neurological disorders.

2. Patients with impaired renal or hepatic function.

3. Any absolute or relative contraindication to study drug.

4. Patients on medications like hypnotics, narcotic analgesics, $\alpha_{2}$ agonists, calcium channel blockers, $\beta$ blockers.

5. Patients with anticipated difficult intubation.

6. Patients intubated after more than 1 attempt or more than 20 seconds.

\section{Pre Anaesthetic Check Up}

All patients were visited on the day prior to surgery and will be explained about the anaesthetic technique and perioperative course. Each patient had a pre anaesthetic check up which includes -

1. Any significant present and past medical/surgical history

2. Physical examination

3. Vital parameters like BP, pulse ,Temperature \& respiratory rate
4. All routine and specific investigations required for major surgeries will be obtained

\section{Procedure}

After taking informed consent and confirming overnight fasting, patient was taken on the recovery room and baseline vitals like B.P., pulse rate, respiratory rate were recorded. After an 18 gauge intravenous (IV) cannula have been inserted at the forearm level.

Randomization was done using chit in box method. Medication preparation was done by another assistant for double blinding.

All the patients were premedicated with five minutes prior to induction of anaesthesia. Heart rate, systolic and diastolic blood pressure were recorded as baseline value.

After preoxygenation induction was done by inj. thiopentone sodium $5 \mathrm{mg} / \mathrm{kg}$ followed by inj. rocuronium $0.6 \mathrm{mg} / \mathrm{kg}$ in intubating dose. Study drugs given slow I.V. 1 minute after rocuronium. Endotracheal intubation was done 2 minutes after rocuronium.

Anaesthesia was maintained with halothane, oxygen and N2O through Bain's circuit on controlled ventilation. Muscle relaxation was done with intermittent dose of rocuronium. At the end of surgery reversal was done with neostigmine $0.05 \mathrm{mg} / \mathrm{kg}$ and glycopyrrolate $0.01 \mathrm{mg} / \mathrm{kg}$.

Hamodynamic data were collected at baseline, just after premedication, just after injecting the drug under study, just after intubation, 1 $\mathrm{min}, 3 \mathrm{~min}$, $5 \mathrm{~min}$ and $10 \mathrm{~min}$ after intubation.

\section{Observations And Results}

Table 1 Demographic Profile

\begin{tabular}{|l|c|c|c|c|}
\hline Demographic Factors & A (Control) & B (Esmolol) & C (Esmolol) & P Value \\
\hline $\begin{array}{l}\text { AGE: (Mean } \pm \text { S.D.) of age } \\
\text { in years }\end{array}$ & $38.8 \pm 09.5$ & $36.4 \pm 10.1$ & $34.9 \pm 10.6$ & \\
\cline { 1 - 3 } SEX: (F/M RATIO IN \%) & $64.9 / 35.1$ & $54.1 / 45.9$ & $45.9 / 54.1$ & P >0.05 \\
\cline { 1 - 3 } $\begin{array}{l}\text { WEIGHT: (Mean } \pm \text { S.D.) of } \\
\text { Weight in kg }\end{array}$ & $54.1 \pm 09.2$ & $54.5 \pm 11.3$ & $55.6 \pm 10.0$ & \\
\hline
\end{tabular}

From table 1, it was observed that there was no significant difference in the mean age of patients, sex distribution and weight of patients $(p>0.05)$ in all the groups. 
Table 2 Mean Heart Rate in various groups (Mean \pm S.D.)

\begin{tabular}{|c|c|c|c|c|c|c|c|c|c|}
\hline \multirow[b]{2}{*}{ Observation Time } & \multicolumn{3}{|c|}{ Control } & \multicolumn{3}{|c|}{ Esmolol } & \multicolumn{3}{|c|}{ Diltiazem } \\
\hline & Mean \pm S.D. & $\begin{array}{c}\mathbf{P} \\
\text { value }\end{array}$ & Sig. & $\begin{array}{l}\text { Mean } \pm \\
\text { S.D. }\end{array}$ & $P$ value & Sig. & Mean \pm S.D. & $P$ value & Sig. \\
\hline Base Line & $82.7 \pm 13.8$ & & & $83.4 \pm 15.2$ & & & $81.0 \pm 12.8$ & & \\
\hline After premedication & $95.4 \pm 15.0$ & 0.0000 & $\mathrm{~S}$ & $86.9 \pm 15.5$ & 0.0017 & $S$ & $83.9 \pm=14.0$ & 0.0990 & NS \\
\hline $\begin{array}{l}\text { After administration of } \\
\text { Drug }\end{array}$ & $94.2 \pm 15.7$ & 0.0000 & $\mathrm{~S}$ & $84.5 \pm 15.5$ & 0.5738 & NS & $90.8 \pm 14.3$ & 0.0000 & $\mathrm{~S}$ \\
\hline Just after intubation & $115.5 \pm 19.1$ & 0.0000 & $\mathrm{~S}$ & $90.3 \pm 15.5$ & 0.0025 & $\mathrm{~S}$ & $104.8 \pm 16.7$ & 0.0000 & $\mathrm{~S}$ \\
\hline 1 Minute after intubation & $113.1 \pm 15.8$ & 0.0000 & $\mathrm{~S}$ & $89.8 \pm 16.0$ & 0.0050 & $\mathrm{~S}$ & $101.2 \pm 15.5$ & 0.0000 & $S$ \\
\hline 3 Minutes after intubation & $107.6 \pm 15.7$ & 0.0000 & $\mathrm{~S}$ & $86.3 \pm 17.4$ & 0.1882 & NS & $95.0 \pm 15.3$ & 0.0000 & $\mathrm{~S}$ \\
\hline 5 Minutes after intubation & $99.0 \pm 13.7$ & 0.0000 & $\mathrm{~S}$ & $82.3 \pm 19.0$ & 0.6363 & $\mathrm{NS}$ & $90.2 \pm 10.7$ & 0.0000 & $\mathrm{~S}$ \\
\hline 10 Minutes after intubation & $97.0 \pm 13.7$ & 0.0000 & $\mathrm{~S}$ & $78.3 \pm 19.0$ & 0.0411 & $\mathrm{~S}$ & $88.2 \pm 10.7$ & 0.0001 & $\mathrm{~S}$ \\
\hline
\end{tabular}

The above table depicts the mean heart rate (Mean \pm S.D.) from the baseline in all three groups at various study intervals. In control group there was significant rise in heart rate just after intubation $(p<0.05)$. The value remained significantly raised during whole study period. In the esmolol group there was small rise in HR after intubation that was significant $(\mathrm{p}<0.05)$ but value touched the baseline within 5 min after intubation that was insignificant $(p>0.05)$ there after there was fall in HR till 10 min. in diltiazem group there was significant increase in HR after intubation $(p<0.05)$ but this rise was significantly less than the control group.

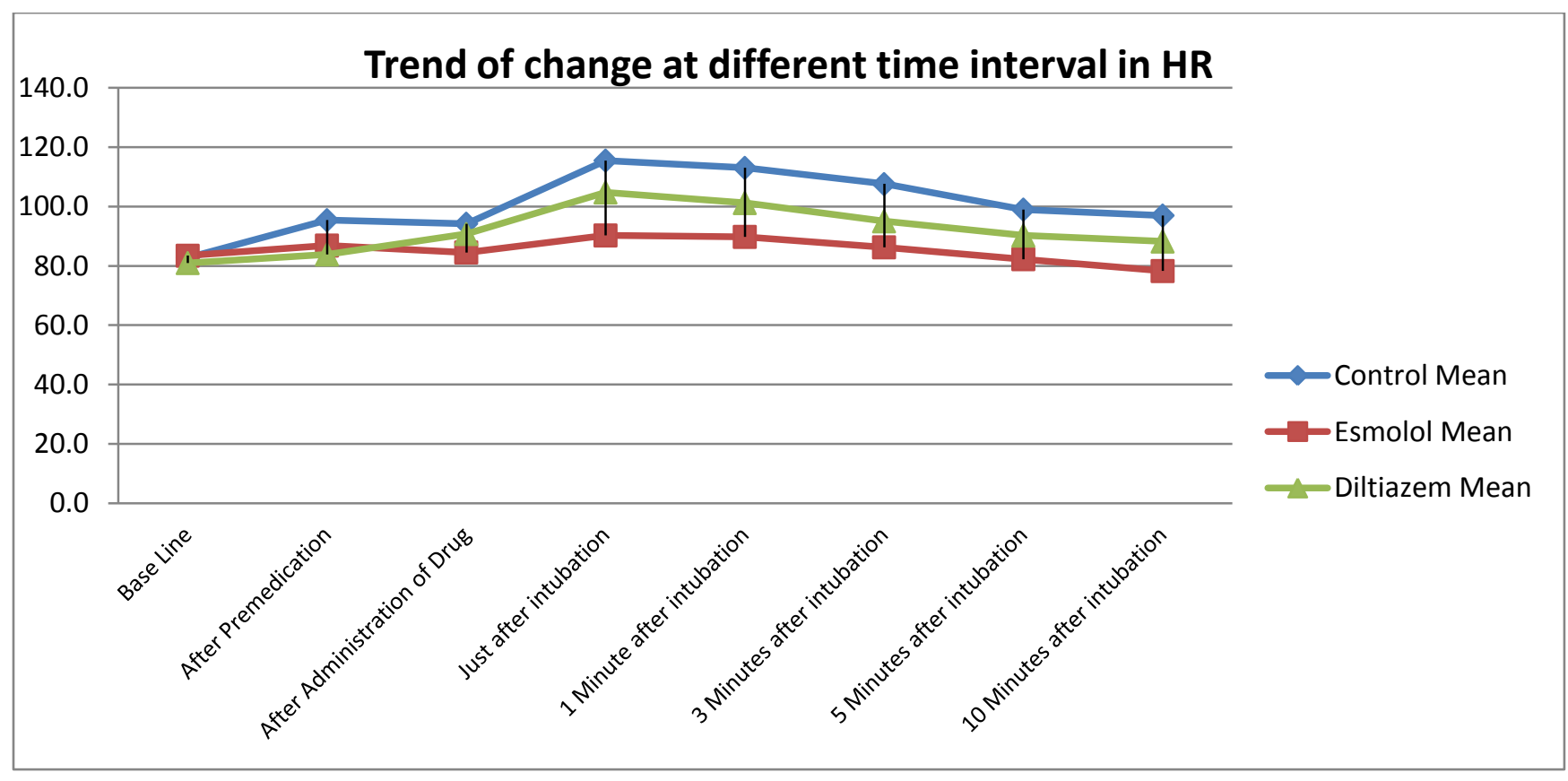

Table 3 Mean Systolic B.P. in various groups (Mean \pm S.D.)

\begin{tabular}{|c|c|c|c|c|c|c|c|c|c|}
\hline \multirow{2}{*}{ Observation Time } & \multicolumn{3}{|c|}{ Control } & \multicolumn{3}{|c|}{ Esmolol } & \multicolumn{3}{|c|}{ Diltiazem } \\
\hline & Mean \pm S.D. & P value & Sig. & Mean \pm S.D. & P value & Sig. & Mean \pm S.D. & P value & Sig. \\
\hline Base Line & $124.0 \pm 11.5$ & & & $122.6 \pm 13.3$ & & & $123.6 \pm 9.9$ & & \\
\hline After premedication & $128.6 \pm 12.2$ & 0.0011 & $S$ & $121.9 \pm 10.1$ & 0.6674 & NS & $131.8 \pm 12.2$ & 0.0000 & $\mathrm{~S}$ \\
\hline After administration of Drug & $125.2 \pm 15.6$ & 0.5673 & NS & $116.9 \pm 10.8$ & 0.0173 & $S$ & $115.9 \pm 20.1$ & 0.0492 & $\mathrm{~S}$ \\
\hline Just after intubation & $161.8 \pm 24.7$ & 0.0000 & $S$ & $143.9 \pm 15.4$ & 0.0000 & $S$ & $141.2 \pm 8.6$ & 0.0000 & $S$ \\
\hline 1 Minute after intubation & $149.1 \pm 21.6$ & 0.0000 & $\mathrm{~S}$ & $141.2 \pm 14.5$ & 0.0000 & $\mathrm{~S}$ & $135.7 \pm 14.0$ & 0.0000 & $\mathrm{~S}$ \\
\hline 3 Minutes after intubation & $139.8 \pm 21.4$ & 0.0000 & $\mathrm{~S}$ & $133.9 \pm 14.7$ & 0.0003 & $\mathrm{~S}$ & $123.8 \pm 18.1$ & 0.9546 & NS \\
\hline 5 Minutes after intubation & $130.0 \pm 18.0$ & 0.0307 & $S$ & $122.9 \pm 12.6$ & 0.8815 & NS & $120.5 \pm 15.5$ & 0.3168 & NS \\
\hline 10 Minutes after intubation & $128.0 \pm 18.0$ & 0.1417 & NS & $118.9 \pm 12.6$ & 0.1592 & NS & $118.1 \pm 15.4$ & 0.0812 & NS \\
\hline
\end{tabular}


The above table 3 depicts the mean SBP (Mean \pm S.D.) from the baseline in all three groups at various study intervals. In control group there was significant rise in SBP just after intubation $(p<0.05)$. The value remained significantly raised during whole study period. In the esmolol and diltiazem group there was significant rise in SBP after intubation but value touched the baseline within $3 \mathrm{~min}$ in diltiazem group and within 5 min.post intubation in esmolol group $(p>0.05)$.no incidence of hypotension was observed in any of the study group.

\section{Trend of change at different time interval in SBP}

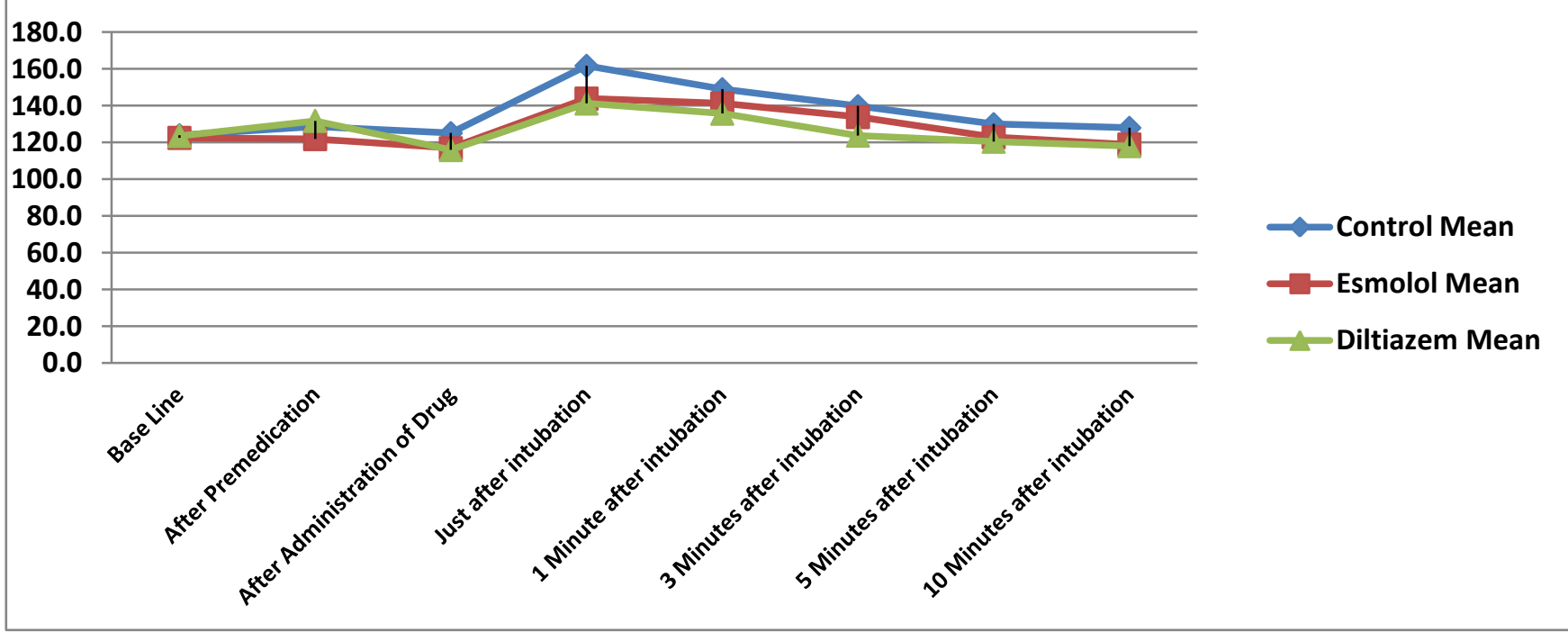

Table 4 Mean Diastolic B.P. in various groups (Mean \pm S.D.)

\begin{tabular}{|l|c|c|c|c|c|c|c|c|c|}
\hline \multirow{2}{*}{ Observation Time } & \multicolumn{3}{|c|}{ Control } & \multicolumn{3}{c|}{ Esmolol } & \multicolumn{3}{c|}{ Diltiazem } \\
\cline { 2 - 11 } & Mean \pm S.D. & P value & Sig. & Mean \pm S.D. & P value & Sig. & Mean \pm S.D. & P value & Sig. \\
\hline Base Line & $81.6 \pm 8.7$ & & & $80.8 \pm 7.6$ & & & $81.9 \pm 6.5$ & \\
\hline After premedication & $84.2 \pm 7.5$ & 0.0155 & S & $81.2 \pm 7.3$ & 0.2176 & NS & $86.8 \pm 6.5$ & 0.0000 & S \\
\hline After administration of Drug & $82.8 \pm 8.3$ & 0.3654 & NS & $79.5 \pm 7.6$ & 0.2734 & NS & $77.7 \pm 12.9$ & 0.0339 & S \\
\hline Just after intubation & $104.3 \pm 17.4$ & 0.0000 & S & $95.8 \pm 12.5$ & 0.0000 & S & $93.4 \pm 9.8$ & 0.0000 & S \\
\hline 1 Minute after intubation & $99.8 \pm 14.6$ & 0.0000 & S & $95.5 \pm 8.9$ & 0.0000 & S & $90.3 \pm 7.8$ & 0.0000 & S \\
\hline 3 Minutes after intubation & $94.7 \pm 16.1$ & 0.0000 & S & $87.9 \pm 8.7$ & 0.0000 & S & $82.8 \pm 10.4$ & 0.6293 & NS \\
\hline 5 Minutes after intubation & $88.2 \pm 12.9$ & 0.0042 & S & $83.0 \pm 8.1$ & 0.1441 & NS & $82.0 \pm 9.8$ & 0.9635 & NS \\
\hline 10 Minutes after intubation & $86.2 \pm 12.9$ & 0.0400 & S & $81.0 \pm 8.1$ & 0.9115 & NS & $80.2 \pm 9.9$ & 0.3182 & NS \\
\hline
\end{tabular}

The above table depicts the mean DBP (Mean \pm S.D.) from the baseline in all three groups at various study intervals. In control group there was significant rise in DBP just after intubation $(p<0.05)$. The value remained significantly raised during whole study period. In the esmolol and diltiazem group there was significant rise in DBP after intubation but value touched the baseline within $3 \mathrm{~min}$ in diltiazem group and within 5 min.post intubation in esmolol group $(p>0.05)$. No incidence of hypotension was observed in any of the study group. 


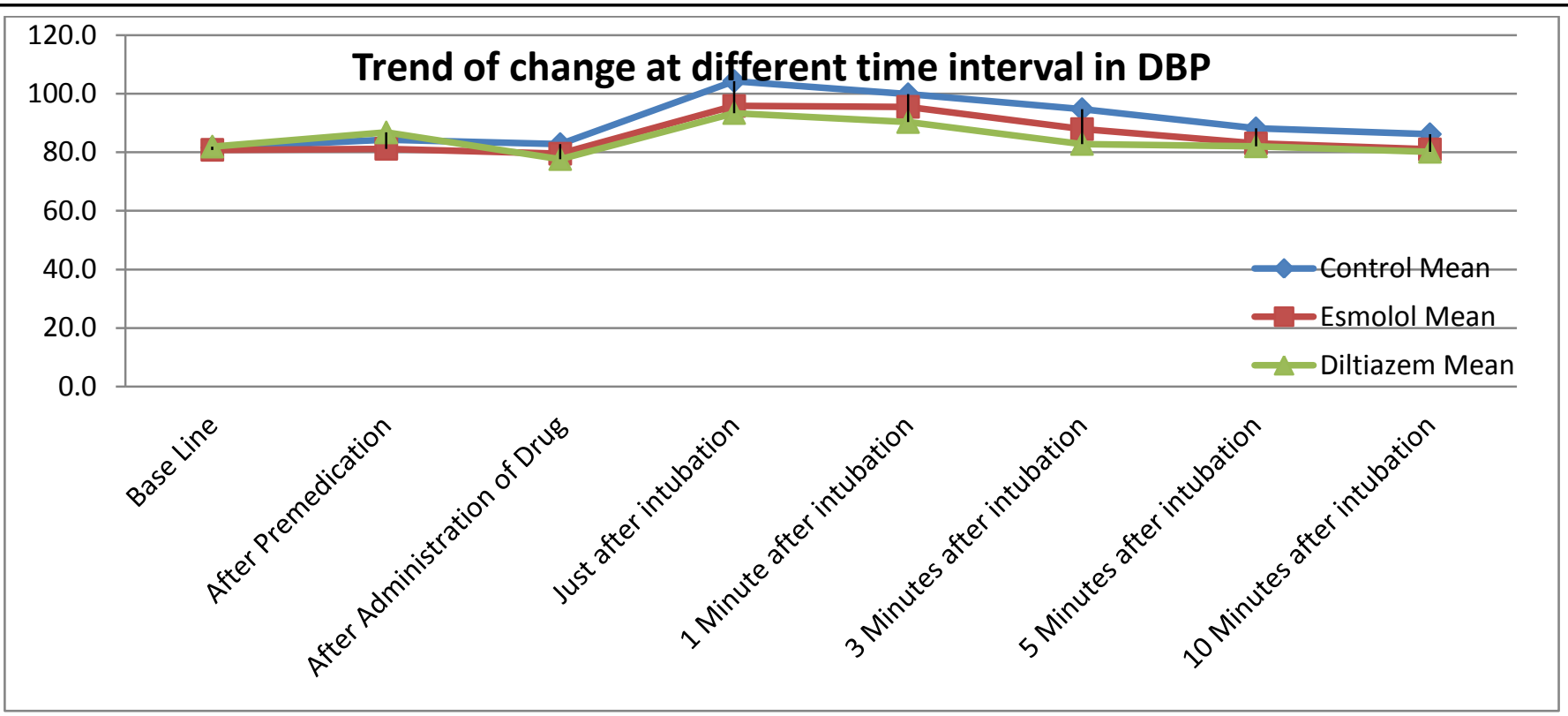

Table 5 Mean B.P. in various groups (Mean \pm S.D.)

\begin{tabular}{|c|c|c|c|c|c|c|c|c|c|}
\hline \multirow{2}{*}{ Observation Time } & \multicolumn{3}{|c|}{ Control } & \multicolumn{3}{|c|}{ Esmolol } & \multicolumn{3}{|c|}{ Diltiazem } \\
\hline & Mean \pm S.D. & P value & Sig. & Mean \pm S.D. & P value & Sig. & Mean \pm S.D. & P value & Sig. \\
\hline Base Line & $95.7 \pm 8.9$ & & & $94.8 \pm 8.1$ & & & $95.8 \pm 6.8$ & & \\
\hline After premedication & $99.0 \pm 8.4$ & 0.0037 & $S$ & $94.8 \pm 7.2$ & 1.0000 & NS & $101.8 \pm 8.0$ & 0.0000 & $S$ \\
\hline After administration of Drug & $96.9 \pm 10.2$ & 0.4248 & NS & $92.0 \pm 7.9$ & 0.0602 & NS & $90.4 \pm 14.7$ & 0.0329 & $\mathrm{~S}$ \\
\hline Just after intubation & $123.5 \pm 18.9$ & 0.0000 & $\mathrm{~S}$ & $111.8 \pm 12.9$ & 0.0000 & $\mathrm{~S}$ & $109.4 \pm 8.3$ & 0.0000 & $\mathrm{~S}$ \\
\hline 1 Minute after intubation & $116.2 \pm 16.4$ & 0.0000 & $S$ & $110.7 \pm 9.1$ & 0.0000 & $\mathrm{~S}$ & $105.5 \pm 8.8$ & 0.0000 & $\mathrm{~S}$ \\
\hline 5 Minutes after intubation & $102.1 \pm 14.2$ & 0.0075 & $S$ & $96.3 \pm 9.0$ & 0.3589 & NS & $94.8 \pm 10.9$ & 0.6395 & NS \\
\hline 10 Minutes after intubation & $100.1 \pm 14.2$ & 0.0590 & NS & $93.9 \pm 9.2$ & 0.5998 & NS & $92.8 \pm 10.9$ & 0.1541 & NS \\
\hline
\end{tabular}

The above table depicts the mean MBP (Mean \pm S.D.) from the baseline in all three groups at various study intervals. In control group there was significant rise in MBP just after intubation $(\mathrm{p}<0.05)$. The value remained significantly raised during whole study period. In the esmolol and diltiazem group there was significant rise in MBP after intubation but value touched the baseline within $3 \mathrm{~min}$ in diltiazem group and within 5 min.post intubation in esmolol group $(p>0.05)$.no incidence of hypotension was observed in any of the study group.

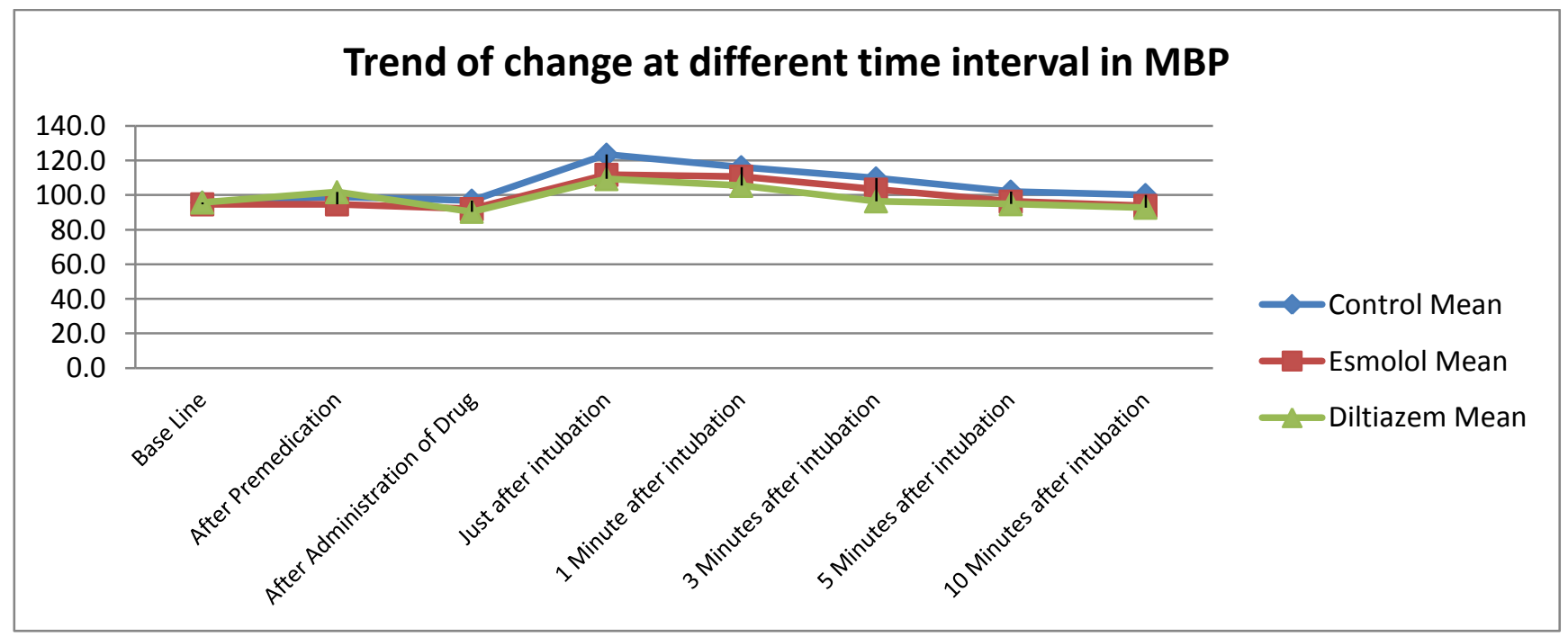


Table 6 Comparison of Mean Baseline Variables in the three groups

\begin{tabular}{|l|c|c|c|c|}
\hline & \multicolumn{3}{|c|}{ Baseline } \\
\hline & HR & SBP & DBP & MBP \\
\hline Control & $82.7 \pm 13.8$ & $124.0 \pm 11.5$ & $81.6 \pm 8.7$ & $95.7 \pm 8.9$ \\
\hline Esmolol & $83.4 \pm 15.2$ & $122.6 \pm 13.3$ & $80.8 \pm 7.6$ & $94.8 \pm 8.1$ \\
\hline Diltiazem & $81.0 \pm 12.8$ & $123.6 \pm 9.9$ & $81.9 \pm 6.5$ & $95.8 \pm 6.8$ \\
\hline P value & $>0.05$ & $>0.05$ & $>0.05$ & $>0.05$ \\
\hline Significance & NS & NS & NS & NS \\
\hline
\end{tabular}

NS = Non Significant $(\mathrm{P}$ value $>0.05) ; \mathrm{S}=$ Significant $(\mathrm{P}$ value $<0.05)$.

It was observed that mean baseline variables (HR, SBP, DBP and MBP) were similar in the three groups and no statistically significant difference was present ( $\mathrm{P}$ value $>0.05)$.

\section{Discussion}

The haemodynamic responses to laryngoscopy and intubation comprising elevation in HR, systolic and diastolic pressure are well known. The potential for life threatening complication associated with these responses especially in patients with preexisting cardiovascular and intracranial disorders is also well documented.

All the three study groups were statistically similar with regards to age and body weight. There was no statically significant difference between the basal value of heart rate, systolic and diastolic blood pressure and mean blood pressure between the three groups in the study.

\section{Heart Rate}

The heart rate was significantly raised after induction in control group and diltiazem group while no rise or rather decrease in heart rate was seen in the esmolol group. This rise in heart rate in control group might be due to glycopyrolate and vasodilatation caused by thiopentone. The additional rise in heart rate in diltiazem group might be due to diltiazem induced peripheral vasodilatation leading to the reflex tachycardia. Immediately after intubation, there was a significant increase in heart rate in control group $(p>0.05)$ and diltiazem group. In esmolol group the heart rate was increased but it was not statistically significant.

The diltiazem group was also found to be inefficient in controlling tachycardia due to this symphathatic stimulation. The significant increase in heart rate in control group and diltiazem group may be associated with $\backslash$ critical increase in myocardial oxygen consumption yet ischemic changes did not appear in any patient probably because the myocardial perfusion pressure was maintained.

The esmolol group were however very effective in controlling tachycardia response associated with laryngoscopy and intubation. Mean heart rate was just minimally raised above the basal value in esmolol group.

Three minutes after intubation significant increase in heart rate in control group $(p>0.05)$.the same was observed at $5 \mathrm{~min} .(\mathrm{p}>0.05)$.

In diltiazem group tachycardia was found to be almost similar to the control group at all the time intervals. Increase in HR slightly lesser than the control group.

Thus diltiazem proved to be ineffective in controlling heart rate response associated with laryngoscopy and intubation.

Individual study on diltiazem was done by santosh kumar et al $(2003)^{11}$. They also found that diltiazem was ineffective in controlling the heart rate.

These finding are consistent with that of Mikawa et al $(1990)^{10}$ who said i.v. diltiazem given 1 min. before laryngoscopy failed to protect against increase in heart rate after laryngoscopy and intubation.

In esmolol group the heart rate showed a very insignificant rise immediately after intubation but at $1 \mathrm{~min}$. It started decreasing and almost touched the baseline value within $5 \mathrm{~min}$. in esmolol group ,the heart rate remained closer to the basal value at all the time intervals and rise in heart rate observed after intubation was significantly lower 
than what observed in other group. So the heart was most effectively controlled by esmolol group. Dr Santosh Kumar et al (2003) ${ }^{11}$ compare the efficacy of I.V esmolol diltiazem and magnesium sulphate. It was found that esmolol proved to be the most effective in attenuating rise in heart rate following laryngoscopy and intubation.

\section{Systolic Blood Pressure}

After intubation the increase in SBP was observed in all the three groups. However,the increase in SBP in control,diltiazem and esmolol was $39 \%$, $12 \%$ and $16 \%$ respectively.

The diltiazem and esmolol group provided significant protection $(\mathrm{p}<0.05)$ compared to the control group in controlling the SBP response in relation to laryngoscopy and intubation.

In control group the SBP remained above the basal value during whole study period. In the diltiazem group, the SBP touched the basal value within 3 min of intubation. In esmolol group, the SBP came down to basal value within 5 min. of intubation.

These result are consistent with the study of Dr Santosh Kumar et al (2003) ${ }^{11}$, who observed that i.v. diltiazem $(0.2 \mathrm{mg} / \mathrm{kg})$ was quite effective in controlling the pressure response associated with laryngoscopy and intubation whereas esmolol $(2 \mathrm{mg} / \mathrm{kg})$ was not that very effective in controlling the pressure response associated with laryngoscopy and intubation .

\section{Diastolic Blood Pressure (DBP)}

Following induction and just after intubation the DBP increased in all the three groups.

It was observed that DBP in the control group increased after intubation but it remained elevated to significant level above the basal value even at 5 min post intubation $(\mathrm{P}<0.05)$.

In diltiazem group the DBP was significantly raised immediately after intubation $(\mathrm{p}<0.05)$ but it got settled down to basal value within 3 min of intubation.

In esmolol group also the elevation in DBP after intubation was highly significant $(p<0.05)$ but it came down to baseline within $5 \mathrm{~min}$ post intubation
Our finding are also similar to the results of mikawa et al (1990) ${ }^{10}$ who found that increase in SBP and DBP was significantly less in diltiazem group $(0.2 \mathrm{mg} / \mathrm{kg})$ compare to control group.

\section{Mean Blood Pressure (MBP)}

After induction and just after intubation the MBP increased in all the three groups.

It was observed that MBP in the control group increased after intubation but value remained significantly raised during whole study period $(\mathrm{P}<0.05)$. In diltiazem group the MBP was significantly raised immediately after intubation $(\mathrm{p}<0.05)$ but it got settled down to basal value within 3 min of intubation. In esmolol group also the elevation in MBP after intubation was highly significant $(p<0.05)$ but it came down to baseline within 5 min post intubation.

Our finding are also similar to the results of mikawa et al (1990) ${ }^{10}$ who found that increase in DBP and MBP was significantly less in diltiazem group $(0.2 \mathrm{mg} / \mathrm{kg})$ compare to control group.

\section{Summary and Conclusion}

1) Definitive haemodynamic response to laryngoscopy and intubation was observed in control group with highly significant increase in heart rate, systolic blood pressure, diastolic blood pressure and mean blood pressure occuring just after intubation compared to the preinduction basal value.

2) Diltiazem was found to be ineffective in controlling the heart rate response related with laryngoscopy and intubation. The intensity and duration of rise in heart rate was almost similar to the control group. Esmolol were very effective in attenuating this tachycardia. The heart rate at all the stages of the study period was significantly lesser in the esmolol group as compare to the placebo.thus esmolol achieved better control over the heart rate among all the study drugs.

3) The systolic blood pressure elevation after intubation in both diltiazem and esmolol 
group was significantly less compared to the control. The value touched the baseline within $3 \mathrm{~min}$ in diltiazem group and within $5 \mathrm{~min}$ in esmolol group, however the rise in SBP was significantly lesser in diltiazem group then in esmolol group. Thus diltiazem achieved much better control on the systolic blood pressure rise related with laryngoscopy and intubation among all the three groups.

4) The diastolic blood pressure after intubation was significantly attenuated by both esmolol and diltiazem. The value touched the baseline within $3 \mathrm{~min}$ in diltiazem group and within $5 \mathrm{~min}$ in esmolol group. Thus diltiazem achieved better control on diastolic blood pressure among all the study drugs.

5) The mean blood pressure elevation after intubation in both diltiazem and esmolol group was significantly less compared to the control.the value touched the baseline within 3 min in diltiazem group and within 5 min in esmolol group. Thus diltiazem achieved much better control on the mean blood pressure rise related with laryngoscopy and intubation among all the three groups.

6) No ECG, abnormality was observed in any patients in any group.

Hence esmolol was the most effective in controlling the heart rate following laryngoscopy and intubation but it was not very effective in attenuating the pressure response related with laryngoscopy. Diltiazem was quite effective in controlling the pressure response but it failed to achieve any control over the heart rate response in relation to laryngoscopy and intubation.

\section{Bibliography}

1. Fox. E.J. Sklar G.S., Hill C.H., Villanueva R., King B.D. Complications related to the pressure response to endotracheal intubation. Anaesthesiology. 1977; 47: 5245.

2. Prys-roberts C., Greene, L.T., meloche, R., Forex. P. studies of anaesthesia in relation to hypertension. II: Haemodynamic consequences of induction and endotracheal intubation. Br. J. Anaesth. 1971; 43: 531.

3. King B.D. harris L.C., Greifenstein F.E., Ellder J.D., Drips, R.D. Reflex circulatory response to direct laryngoscopy and tracheal intubation performed during general anaesthesia. Anesthesiology 1951; 12: 556-66.

4. Denlinger J.K., Ellison, N., Ominsky A.J. Effects of intratracheal lidocaine on circulator response to tracheal intubation. Anesthesilogy 1974; 41: 409-12.

5. Dahlgran N., Messeter K. Treatment of stress response to laryngoscopy and intubation with fentanyl. Anaesth. 1981; 36: 1002-6

6. Dich-Nielsen. J., Hole. P., Lang- Jensent. Owen-Falkenberg. A., Skovsted, P.: The effect of intranasally administered nitroglycerine on the blood pressure response to laryngoscopy and intubation in the patients undergoing coronary artery bypass surgery. Acta Anaesh. Scand. 1986; 30: 23.

7. Curran, J., Crowley, M. Sullivan, G.O.: Droperidol and endotracheal intubation. Attenutation of pressor response to laryngsocopy and intubation. Anaesthasia 1980; 35: 290.

8. Kopriva, C.J., Brown, A.C.D. Pappas, G.: Haemodynamic during general anaesthesia in patients receiving propanolol. Anaesthaesiology. 1978; 48: 28.

9. Elkayam. Uri and Wilbert, S. Aronow: Glyceryl trinitrate (Nitroglycerine) ointment and isosorbide dinitrate: review of their pharmacological properties and therapeutic use. Drugs 1982; 23: 165.

10. K. Mikawa, n. Nishiva, N. Mackawa \& H.O. Bara: Comparison of nifedipine. 
Diltiazem \& verapamil for controlling the cardiovascular response related to tracheal intubation. British Journal of Anaesthesia 1996; 76: 221-226.

11. Santosh Kumar, MN Mishra, L.S. Mishra, Sapna Bathla: Comparative study of the efficacy of the esmolol, diltiazem and magnesium sulphate in attenuating haemodynamic responses to laryngoscopy and tracheal intubation. Indian J. Anaesh 2003; 47(1): 41-44 